\title{
AEROSOL PENICILLIN IN THE OXYGEN TENT
}

BY

\author{
F. A. KNOTT, M.D., F.R.C.P, D.P.H., and NEVILLE SOUTHWELL, M.B., M.R.C.P.
}

(From the Department of Bacteriology, Guy's Hospital, London)

Penicillin is readily absorbed through the lungs when its solution in saline or water is inspired in the form of an ' aerosol' mist from a closed inhaler (Barach et al., 1945; Mutch and Rewell, 1945) or even when dispersed into the atmosphere of a small room (Knott and Clark, 1945). Bacteriostatic concentrations in both blood and urine can be attained. Good therapeutic effects, particularly in respiratory tract infections, have been described (Vermilye, 1945). We have therefore made observations upon the absorption of penicillin by children in oxygen tents into which the aerosol was being discharged continuously. If a satisfactory blood and tissue concentration could be maintained the method promised the advantage that in children with severe bronchial or pulmonary infections and too young or too ill to tolerate any form of closed inhaler there would, without any disturbance of the patient, also be continuous direct application of penicillin to the infected areas.

From previous experiment we knew that atmosphere with relatively high concentration of penicillin aerosol could be inhaled for considerable periods without discomfort or after-effects of any kind. It was possible to remain for an hour or more in a small room visibly misty with aerosol and yet, after the first few moments, be virtually unaware of its presence. By collecting known volumes and bringing them into contact with small measured amounts of cold water of which the penicillin content was subsequently estimated, we found that these well-tolerated atmospheres carried as much as 35 units per litre.

It was therefore decided to devise some simple form of aerosol generator which, driven by pressure from an oxygen cylinder, would steadily discharge the mist into an ordinary oxygen tent. The apparatus had to fix firmly to the frame of the cot or bed, be of stout unbreakable construction, capable of working continuously for several hours, easy to clean and simple to re-fill. The generator which, with the makers' assistance, was finally developed and used in these experiments is illustrated in figs. 1 and 2.

Except for the thick glass penicillin reservoir at the base, the generator is of all-metal construction. The internal jet, the baffle plate and metal ducts are easily cleaned with water and can be sterilized when necessary. The glass reservoir has the advantage that consumption of the penicillin solution is easily watched. But in ward practice we found that all-

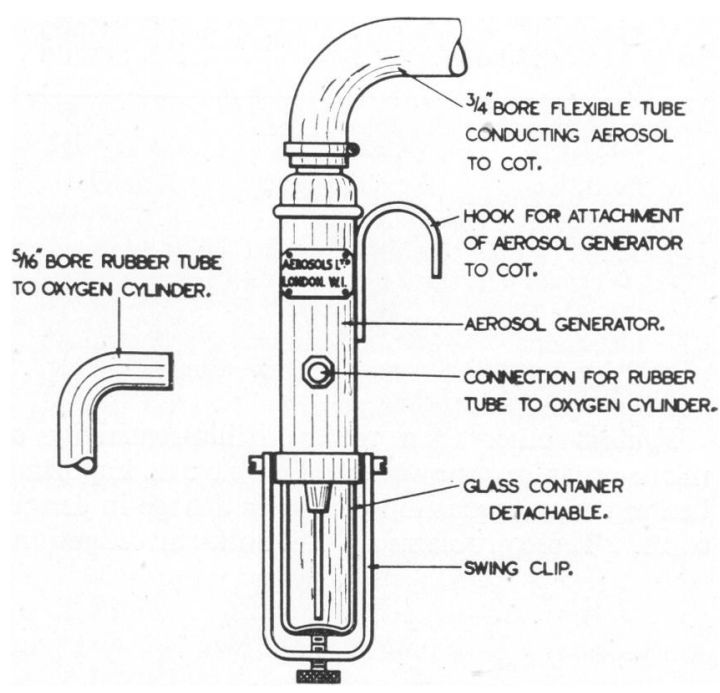

Fig. 1.

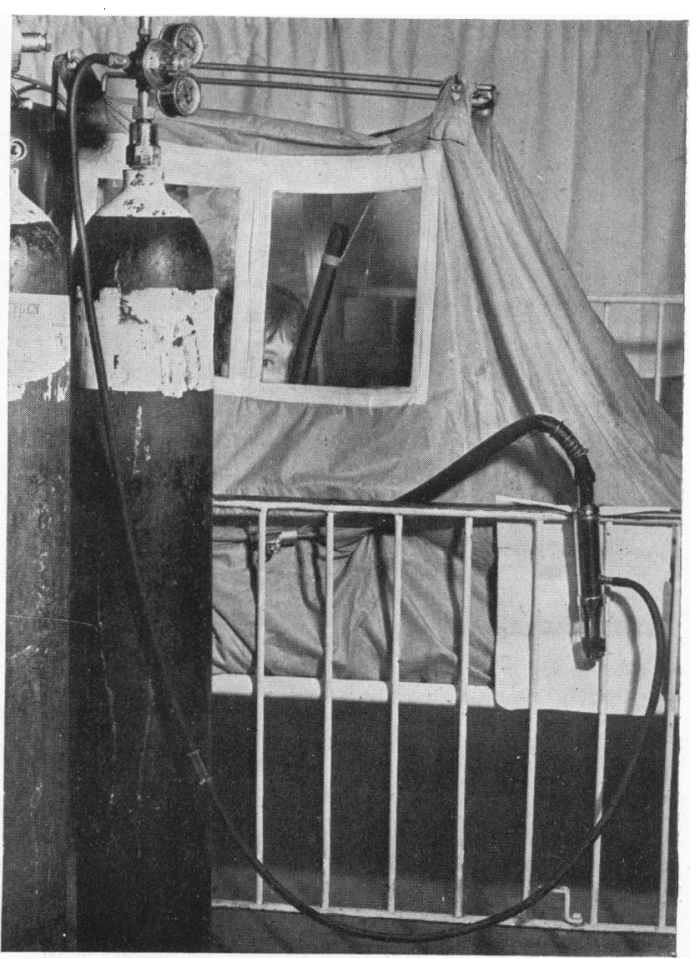

FIG. 2. 
glass jets were too frequently broken during cleaning. Rubber tubes of appropriate bore connect the generator with the oxygen cylinder and one of the lateral openings in the tent. At the end of the wide delivery tube is a short string leading to a spring clip which, attached inside to the fabric of the tent, lightly holds it in any desired position. In all our tests the medium size tents supplied by Oxygenaire Ltd. were used and their volume as set up averaged approximately 5,500 litres. Two oxygen cylinders were always used, one to operate the tent in the usual way, but, in view of the additional oxygen coming through the generator, we adopted the rather low rate of flow of about 4 litres per minute. The other cylinder was run at whatever rate produced a steady, easily visible stream of mist from the delivery tube. This flow was usually also about 3 to 4 litres per minute. If only one cylinder is available the flow can be divided by a Y-piece with a flow-meter attached to each arm, but in practice we found it preferable always to use separate cylinders. Ventilation control was then much better.

The penicillin solution placed in the generator contained 20,000 to 25,000 units per $\mathrm{ml}$. in sterile normal saline. For cases 1 to 3 calcium penicillin was used, but in the remaining tests only the sodium salt was available. Some of the observers already quoted describe the calcium salt as producing the better aerosol, but we cannot pronounce on this point. Both were quite effective for our purpose. At the above rate of flow from the cylinder, 4 to $5 \mathrm{ml}$. of the solution are dispersed as aerosol within the tent per hour. With the ventilation flow mentioned, the atmosphere within the tent contained 15 to 20 units of penicillin per litre. The content of the air actually inspired may often have been higher because the end of the delivery tube was placed to give good concentration near the face. We found it important to note at intervals whether a visible stream of mist was flowing steadily from the tube because with time the oxygen flow tends to fall and the valve may require opening a little until the mist can again be seen.

Through the kindness of its Director we had opportunity to examine nine patients in the Children's Department. Each remained under the above conditions in a tent for periods up to three hours. None showed any sign of distress. Two slept, five played with toys or books, and two, both of rather nervous type, cried a little at first but nothing more. Two of these children were suffering from bronchitis but the others were, as regards serious respiratory tract infection, virtually normal, having only slight colds. No therapeutic deductions are therefore attempted from this small group. The results of their examination are put forward simply as illustrating the degree of penicillin absorption obtainable by the method. In view of this survey treatment of a series of children suffering from really active infection has been undertaken in the Department. The early results have been decidedly encouraging and we are therefore prompted to give this preliminary description not only of the technique but of the experimental results in general because they have, we think, a significant bearing upon the whole rationale of the administration of penicillin by inhalation.

Each of these children emptied its bladder immediately before going into the tent. For examination they were removed and the skin surfaces of the genital areas and arms washed to avoid all traces of penicillin. Specimens of urine and venous blood were then collected, and also some respiratory tract cultures. These were all immediately taken to the laboratory for examination.

Of the urines the specific gravity and the reaction were first noted and the latter then brought to neutrality. After high-speed centrifuging to remove practically all debris and bacteria, the penicillin content of the supernatant urine was estimated in the usual way by setting up serial dilutions in parallel with a known saline solution, using the Oxford $\mathrm{H}$ strain of Staphylococcus aureus as the test organism.

The sera were examined according to the method modified from that of Fleming (1943) and recently advocated by Lourie, Collier, Ross, Robinson and Nelson (1945). Here also a series of dilutions is run parallel with those of a known saline solution. These observers found that by their method the minimal fully bacteriostatic concentration of penicillin in serum was about 0.07 units per ml. Our results are summarized in table 1 .

TABLE 1

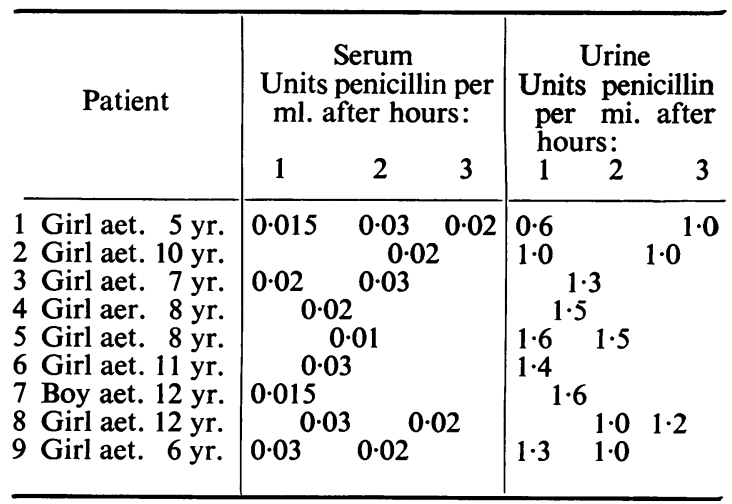

As regards the penicillin content of the venous blood, these children showed relatively very low figures. In no case did they reach the minimal fully bacteriostatic level mentioned above and it is to be noted that for this level Garrod (1944) suggested an even slightly higher figure, namely, $0 \cdot 1$ units per $\mathrm{ml}$. On the other hand these children had very large quantities in the urine. The concentration of penicillin tended to vary inversely with the specific gravity, but generally the urine carried 40 to 50 times as much as the venous blood per volume.

The relatively high urinary figure might well arise from the rapidity with which penicillin is known to be excreted. But the blood levels seemed to be very low to provoke this rate and it occurred to us that penicillin absorbed mainly into the pulmonary 
circulation might show some peculiarities in its subsequent distribution.

Full-grown rabbits were therefore placed under conditions as nearly as possible the same as those encountered by the children. Instead of an actual tent a more or less cubical glass-sided cupboard (approximately 5,000 litres) was used. Ventilation, oxygen flow and aerosol dispersion were maintained as before. The animals took very little notice of the mist and showed no sign whatever of distress. They remained in the cupboard for an hour to an hour and a half. On removal they were instantaneously killed by a single blow on the back of the head and the thorax and abdomen were at once opened. By needle and syringe aspiration blood samples were at once taken from the right and left ventricles. Meanwhile an assistant had clamped off a peripheral area of the lung to arrest all circulation. Avoiding large bronchi, about $2 \mathrm{~g}$. of the isolated lung tissue was cut away with scissors, quickly weighed, and ground up with sand in $10 \mathrm{ml}$. of normal saline. Filtration followed immediately and we estimated the penicillin content of the filtrate. The penicillin levels at the different sites are set out in table 2 .

\section{TABLE 2}

\begin{tabular}{cccc} 
Rabbit & \multicolumn{2}{c}{ Serum units per ml. } & Lung \\
& Right ventricle & Left ventricle & Units per g. \\
1 & 0.02 & 0.35 & 3.1 \\
2 & 0.01 & 0.25 & 2.0 \\
3 & 0.03 & 0.35 & 0.8 \\
4 & 0.015 & 0.20 & 1.2 \\
5 & 0.03 & 0.30 & 3.0
\end{tabular}

It will be seen that after its absorption through the lungs there is decidedly more penicillin in the blood of the left ventricle than in that of the right. Accordingly there must be a much higher concentration passing to the tissues in the arterial blood than that indicated by the results of venepuncture estimations. The low blood figures in the children are not necessarily an index of the bacteriostasis to be expected. But a further significant result of the animal tests is the demonstration of the very considerable concentration of penicillin found in the peripheral lung. The average figures for the different sites are: Right ventricle blood 0.02 units per ml., left ventricle blood 0.29 units per $\mathrm{ml}$. and lung 2.0 units per $\mathrm{g}$.

\section{Discussion}

If one adds to the above evidence the fact that nose and throat swabbings and any sputum taken from the children after only a quarter-of-an-hour in the tent are loaded with penicillin and when plated and incubated will grow no penicillinsensitive organisms, it seems clear that inhalation of the aerosol stands a good chance of influencing respiratory tract infections favourably quite apart from any effect of the penicillin circulating in the blood. That free absorption into the blood stream does occur cannot be in doubt and disappointing though the low venous blood concentrations may at first sight appear to be, the above direct animal experiments indicate that during continuous inhalation of the aerosol penicillin is reaching distant tissues in significant quantities. Therefore we feel that the method, which is quite simple in operation, causes no undue nursing complications and is perfectly well tolerated by patients, deserves careful clinical trial.

\section{Summary}

A method is described by which continuous inhalation of penicillin aerosol can be combined with the treatment in oxygen tents of children suffering from acute respiratory tract infections.

As a result of examining specimens from children in such tents and of direct animal experiment, figures are given for the blood, urinary and pulmonary penicillin concentrations which may be obtained by the method.

There is relatively high concentration in the lung and in the arterial blood during continuous inhalation.

We wish to express our sincere thanks to Dr. R. W. B. Ellis for placing the facilities of his Department so freely at our disposal. For the penicillin used we are greatly indebted to the Penicillin Clinical Trials Committee of the Medical Research Council. In the wards the assistance of Miss Duncombe, Sister in charge, has been invaluable, and to Mr. W. H. Clark, F.I.M.L.T., and Mr. A. C. Lock, M.I.E.E., we are most thankful for unfailing technical advice. The generator and the drawing for fig. 1 were made by Aerosols Ltd., 10, Portman Street, W.1.

\section{REFERENCES}

Barach, A. L., Silberstein, F. H., Oppenheimer, E. T., Hunter, T. and Soroka, M. (1945). Ann. Intern. Med., 22, 485.

Fleming, A. (1943). Lancet, 2, 434.

Garrod, L. P. (1944). Brit. Med. J., 1, 528.

Knott, F. A., and Clark, W. H. (1945). Lancet, 1, 468.

Mutch, N., and Rewell, R. E. (1945). Ibid., 1, 650.

Lourie, E. M., Collier, H. J. O., Ross, A. D. F., Robinson, D. T., and Nelson, R. B. (1945). Ibid., 2, 696.

Vermilye, H. N. (1945). J. Amer. Med. Ass., 129, 250. 